\title{
Predictors of Hospitalization in Vitamin K Antagonist Users Presenting with Bleeding at the Emergency Department
}

\author{
Alan Fabiani Chiaparini, ${ }^{\circledR}$ Paola Stefania Bohrer Rabaioli, ${ }^{\circledR}$ João Slaviero, ${ }^{\circledR}$ Cinthia Scatolin Tem-Pass, \\ Hugo Antonio Fontana Filho, ${ }^{\circledR}$ Iran Castro, ${ }^{\circledR}$ Eduardo Dytz Almeida, ${ }^{\circledR}$ Tiago Luiz Luz Leiria ${ }^{\circledR}$ \\ Instituto de Cardiologia, Porto Alegre, RS - Brazil
}

\section{Abstract}

Background: Vitamin $\mathrm{K}$ antagonists (VKA) are indicated for the prevention of thromboembolic events and reduction of mortality in patients with atrial fibrillation and patients with valvular prostheses. However, their use is associated with bleeding complications and hospitalizations. Predictors of hospital admission for bleeding in these patients are poorly known.

Objectives: To define the predictors for hospitalization of VKA users who seek emergency care due to bleeding.

Methods: Single-center, cross-sectional study, with retrospective analysis of electronic medical records from 03/01/2012 to $02 / 27 / 2017$. Clinical and laboratory variables were compared between patients who were hospitalized and those who were not. A logistic regression model as used, in which the variables were included using the Backward stepwise method, with a p value of 0.05 as the input criterion, a removal value of 0.20 and a confidence interval of $95 \%$. The p-value was considered statistically significant when $<0.05$.

Results: A total of 510 patients with bleeding were included, of whom 158 were hospitalized. Predictors of hospitalization were: INR at supratherapeutic levels (OR 3.45; P <0.01; 95\% CI 1.58 - 7.51), gastrointestinal bleeding (OR 2.36; P <0.01; CI 95\% 1.24 - 4.50), drop in hemoglobin (OR 6.93; P <0.01; 95\% CI 3.67 - 13.07), heart failure (OR 1.96; P 0.01; 95\% CI 1.16 - 3.30) and need for blood transfusion (OR 8.03; P <0.01; 95\% CI 2.98 - 21.64).

Conclusion: Drop in hemoglobin, heart failure, INR at supratherapeutic levels, gastrointestinal bleeding and need for blood transfusion were associated with hospitalization. Identification of these factors in the initial evaluation would help to define which patients will demand more intensive care.

Keywords: Hemorrhage; Emergencies; Warfarin; Platelet Aggregation.

\section{Introduction}

Vitamin $\mathrm{K}$ antagonists (VKA) are indicated for the prevention of thromboembolic events and reduction of mortality in patients with atrial fibrillation (AF) and patients with prosthetic heart valves. ${ }^{1-4}$ However, hemorrhagic complications of VKA therapy are frequent, due to genetic polymorphisms of VKA enzymes in the liver, or pharmacological and dietary interactions. ${ }^{5}$

VKA is still the only option for patients with mechanical prostheses and valvular AF. 3,4,6,7 Warfarin is the only VKA currently available in the United States, and here in Brazil, phenprocoumon, a long-acting oral anticoagulant, has been also used. Bleeding in patients treated with VKA is a common cause of unscheduled emergency room visits and consequent hospitalization, ${ }^{8}$ with a significant impact on social healthcare costs. ${ }^{9}$

The number of studies on VKAs has been decreasing in recent years. In particular, studies reporting the prevalence and management of hemorrhagic complications (such as stroke) in emergency services are scarce, with high methodological heterogeneity. ${ }^{10-15}$ To date, there is little knowledge about the reasons of hospitalization among these patients. Thus, this study aims to evaluate the 
predictive factors of hospitalization in VKA users who seek emergency care due to bleeding.

\section{Methods}

This was a single-center, cross-sectional study carried out in a tertiary cardiology hospital, with retrospective analysis of electronic medical records. Emergency room recorded from 03/01/2012 to 02/27/2017 were reviewed if the following ICD-10 codes where entered: coumarin poisoning ( $\mathrm{T} 45.5$ ), bleeding esophageal varices (I 85.0), acute post-hemorrhagic anemia (D 62.0), acute hemorrhagic gastritis (K 29.0), hematemesis (K 92.0), conjunctival hemorrhage $(\mathrm{H}$ 11.3), upper gastrointestinal bleeding (K 92.2), upper gastrointestinal bleeding due to duodenal ulcer $(\mathrm{K}$ 26.0), upper gastrointestinal bleeding due to gastric ulcer ( K 25.0), lower gastrointestinal bleeding (K 92.2), unspecified non-traumatic intracranial hemorrhage (I 62.9), unspecified respiratory tract bleeding ( $\mathrm{R}$ 04.9), retinal hemorrhage (H 35.6), subarachnoid hemorrhage (I 60.9), melena ( K 92.1), adverse effect of coumarins (Y 44.3), epistaxis (R 04.0) and long-term use of oral anticoagulants (Z 92.1). Data collection was carried out by trained medical students and cardiology fellows.

Patients older than 18 years who had bleeding while using VKA were included. Those with bleeding not related to the use of the drugs in question, those with supratherapeutic international normalized ratio (INR) without bleeding, with inadequately filled medical records and new visits to patients who had already been selected were excluded. Patients included in the study were divided into two groups according to the need for hospitalization or not.

The risk of thromboembolism and bleeding in patients with non-valvular AF was estimated by the CHA2DS2VASc (congestive heart failure/ left ventricular dysfunction, hypertension, age $>75$, diabetes mellitus, stroke / transient ischemic attack / thromboembolism, vascular disease [prior myocardial infarction, peripheral artery disease, or aortic plaque], age 65-74, and sex category [female gender]) and the HAS-BLED (hypertension, abnormal renal and liver function, stroke, bleeding, labile INRs, elderly, and drug or alcohol consumption). Bleeding severity was assessed using the BARC (Bleeding Academic Research Consortium) and GUSTO (The Global Use of Strategies to Open Occluded Arteries) scores, and medications that could interact with VKA, increase the risk of bleeding, and gastric protectors were reviewed.
Recommendations for conducting cross-sectional studies were followed according to the STROBE Statement (https://www.strobe-statement.org). The study was approved by the institutional ethics committee.

\section{Statistical Analysis}

Continuous variables were described by means and standard deviations and categorical variables as absolute and relative frequencies. The Shapiro-Wilk test was used to assess the normality of quantitative variables. For comparison between categorical variables, the chi-square test or Fisher's exact test was used, when appropriate. For comparisons of continuous variables between the groups, the unpaired Student's $t$ test was used. The p-value was considered statistically significant when $<0.05$.

A binary logistic regression model was performed, and the variables were included using the backward stepwise method (probability), using a p-value of 0.05 as the inclusion criterion, a removal value of 0.20 and a confidence interval of $95 \%$. The variables with a statistically significant difference in the comparative analysis between the groups and those considered relevant by the researchers were selected to enter the model. Statistical analyses were performed using the Statistical Package for the Social Science version 25 (SPSS).

\section{Results}

Of the 145,122 patient visits in the emergency department during the analyzed period, 1,823 were screened. After applying the exclusion criteria, 510 patients were included in the study. Of these, $44.8 \%$ required hospitalization.

Table 1 describes the main clinical characteristics of patients admitted or discharged from the emergency department. Most patients were women (52.7\%) and elderly, with an average age of 65.3 years, with no difference between the groups. There was a high prevalence of heart failure, renal failure, and coronary artery disease (CAD) among the hospitalized patients. The main antiplatelet drugs prescribed for outpatients were acetylsalicylic acid and clopidogrel. The most used VKA was warfarin $(77.3 \%)$, with no difference between groups.

VKAs were mainly indicated for patients with AF or atrial flutter, with no difference between groups; however, venous thromboembolism was found to be significantly more common in outpatients than hospitalized patients (Table 2). 
Table 1 - Clinical characteristics of patients who were hospitalized or not after emergency care $(n=510)$

\begin{tabular}{|c|c|c|c|}
\hline & Discharged from the mergency department $(n=349)$ & $\begin{array}{l}\text { Hospital dmission } \\
\qquad(\mathrm{n}=161)\end{array}$ & $\mathbf{p}$ \\
\hline Female gender, $\mathrm{n}(\%)$ & $185(53)$ & $84(52)$ & 0.92 \\
\hline Age & $66.8(+13.6)$ & $64.6(+12.3)$ & 0.08 \\
\hline Diabetes mellitus (\%) & $64(18.3)$ & $39(24.2)$ & 0.12 \\
\hline Systemic arterial hypertension, $\mathrm{n}(\%)$ & $264(75.6)$ & $132(82)$ & 0.13 \\
\hline Stroke or TIA, n (\%) & $34(9.7)$ & $15(9.3)$ & 1.00 \\
\hline Heart failure, n (\%) & $149(39.8)$ & $85(52.8)$ & $<0.01$ \\
\hline Ejection fraction \%, mean (DP) & $57.9(+14.4)$ & $55.7(+17.1)$ & $<0.01$ \\
\hline PAD, n (\%) & $10(2.9)$ & $8(5.0)$ & 0.30 \\
\hline Renal Failure, n (\%) & $20(5.7)$ & $26(16.1)$ & $<0.01$ \\
\hline Liver Disease, n (\%) & $3(0.9)$ & $5(3.1)$ & 0.11 \\
\hline Smoking, n (\%) & $105(30.1)$ & $59(36.6)$ & 0.15 \\
\hline Alcoholism, n (\%) & $5(1.4)$ & $7(4.3)$ & 0.05 \\
\hline Lipid disorder, $\mathrm{n}(\%)$ & $115(33)$ & $63(39.1)$ & 0.19 \\
\hline Coronary heart disease, n (\%) & $101(28.9)$ & $68(42.2)$ & $<0.01$ \\
\hline HCM, n (\%) & $2(0.6)$ & $2(1.2)$ & 0.59 \\
\hline COPD, n (\%) & $14(4)$ & $10(6.2)$ & 0.36 \\
\hline CHA2DS-VASC2, média (DP) & $4.14(+1.47)$ & $3.67(+1.36)$ & 0.01 \\
\hline HASBLED, média (DP) & $3.73(+1.25)$ & $3.11(+1.2)$ & $<0.01$ \\
\hline Antiplatelet use, n (\%) & $158(45.3)$ & $39(24.2)$ & $<0.01$ \\
\hline ASA & $148(42.4)$ & $37(23)$ & $<0.01$ \\
\hline Clopidogrel & $40(11.5)$ & $6(3.7)$ & $<0.01$ \\
\hline Ticagrelor & $1(0.3)$ & 0 & 1.00 \\
\hline Ticlopidine & $2(0.6)$ & $1(0.6)$ & 1.00 \\
\hline Anticoagulant n (\%) & & & 0.36 \\
\hline Warfarin & $274(78.5)$ & $120(74.5)$ & \\
\hline Phenprocoumon & 75 (21.5) & $41(25.5)$ & \\
\hline \multicolumn{4}{|l|}{ Current medications, n (\%) } \\
\hline Amiodarone & $42(12)$ & $12(7.5)$ & 0.12 \\
\hline NSAID & $4(1.1)$ & $2(1.2)$ & 1.00 \\
\hline Calcium channel blocker & $12(3.4)$ & $8(5)$ & 0.46 \\
\hline Anticonvulsant & $3(0.9)$ & $1(0.6)$ & 1.00 \\
\hline Antibiotics & $5(1.4)$ & $2(1.3)$ & 1.00 \\
\hline Statin & $205(58.7)$ & $81(50.3)$ & 0.08 \\
\hline Digoxin & $52(14.8)$ & $29(18.4)$ & 0.18 \\
\hline Fibrate & $6(1.7)$ & $1(0.6)$ & 0.44 \\
\hline
\end{tabular}


Table 2 - Reason for anticoagulation of patients who were hospitalized or not after emergency care $(n=510)$

\begin{tabular}{|c|c|c|c|}
\hline Reason for anticoagulation, $\mathrm{n}(\%)$ & $\begin{array}{l}\text { Discharged from the mergency department } \\
\qquad(\mathrm{n}=349)\end{array}$ & $\begin{array}{l}\text { Hospital dmission } \\
\qquad(\mathrm{n}=161)\end{array}$ & $\mathrm{p}$ \\
\hline Atrial fibrillation or flutter & $238(68,2)$ & $121(75,2)$ & 0,11 \\
\hline Prosthetic heart valve & $119(34,1)$ & $50(31,1)$ & 0,54 \\
\hline Venous thromboembolism & $23(6,6)$ & $3(1,9)$ & 0,02 \\
\hline Left ventricular thrombus & $11(3,2)$ & $5(3,1)$ & 1,00 \\
\hline AMI; low EF & $5(1,4)$ & $2(1,2)$ & 1,00 \\
\hline Others & $6(1,7)$ & $5(3,1)$ & 0,33 \\
\hline
\end{tabular}

Gastrointestinal, intra-abdominal, and central nervous system bleeding were more frequent in patients who were hospitalized. Genitourinary bleeding, epistaxis, oral cavity, and conjunctival bleeding were more prevalent in those who did not require hospitalization (Table 3).

Most patients had supratherapeutic INR levels, especially among those who were hospitalized. Drop in hemoglobin levels, use of vitamin K, blood transfusions and use of plasma, as well as more important bleeding were also more frequent in this group (Table 4).

Figure 1 shows the results of the binary logistic regression between the groups, identifying the variables with the strongest association with the need for hospitalization by VKA users experiencing bleeding. Predictors of hospitalization were: INR at supratherapeutic levels (OR 3.45; P <0.01; 95\% CI 1.58 - 7.51), gastrointestinal bleeding (OR 2.36; $\mathrm{P}<0.01$; CI $95 \% 1.24$ - 4.50), drop in hemoglobin (OR 6.93; $\mathrm{P}<0.01$; $95 \%$ CI 3.67 - 13.07), heart failure (OR 1.96; P $0.01 ; 95 \%$ CI 1.16 - 3.30) and need for blood transfusion (OR 8.03; $\mathrm{P}<0.01 ; 95 \%$ CI 2.98 - 21.64).

\section{Discussion}

Our study reports the experience of an emergency department regarding the management of hemorrhagic complications in anticoagulated stroke patients by means of a five-year retrospective review. According to the study by Shehab et al., ${ }^{8}$ for every 1,000 patients who seek emergency care in the United States in 20132014, four were due to adverse medication events, mainly bleeding complications of oral anticoagulants, especially warfarin. Furthermore, there was a need for hospitalization in practically half of the cases. ${ }^{8}$

In our registry, the main reasons of hospitalizations for bleeding were gastrointestinal bleeding, followed by spontaneous bleeding, and genitourinary and cutaneous hematomas. These data are in line with other studies on the subject. ${ }^{8,10,12,14,16,17}$ Gastrointestinal bleeding site was a predictor of hospitalization, probably due to its higher severity and the need for diagnostic or therapeutic endoscopic procedures.

With regard to comorbidities, heart failure was associated with a greater need for hospitalization. This finding may be explained by the fact that heart failure patients usually have more severe conditions, with more comorbidities, hence requiring greater care.

The intensity of anticoagulation is one of the factors that increase the risk of bleeding., ${ }^{5,7}$ This fact may justify the higher hospitalizations of patients with INR at supra-therapeutic levels. Real-life reports show that $34 \%$ to $51 \%$ of stroke patients who seek emergency care, have an INR above the recommended level. ${ }^{12-14,18,19}$ In our study, these numbers were even higher, probably because we only evaluated patients presenting with bleeding. Considering that an inadequate anticoagulation control can lead to higher morbidity and an increase in public health expenditures, population educational strategies, in addition to a close and continuous medical follow-up are essential, especially at the primary care level.

Anticoagulation reversal is necessary in patients with very high INR or active hemorrhage who will undergo urgent, invasive procedures. In this regard, low doses of vitamin $\mathrm{K}$ can be used in conjunction with the suspension of anticoagulation in patients taking VKAs. ${ }^{3,5,7}$ Despite the few studies in the reviewed literature, the prescription of 
Table 3 - Bleeding site of patients who were hospitalized or not after emergency care $(n=510)$

\begin{tabular}{|c|c|c|c|}
\hline & $\begin{array}{l}\text { Discharged from the emergency epartment } \\
\qquad(\mathrm{n}=349)\end{array}$ & $\begin{array}{l}\text { Hospital Admission } \\
\qquad(\mathrm{n}=161)\end{array}$ & p \\
\hline \multicolumn{4}{|l|}{ Bleeding site, $\mathrm{n}(\%)$} \\
\hline Gastrointestinal & $42(12)$ & $85(52.8)$ & $<0.01$ \\
\hline Spontaneous cutaneous hematoma & $95(27.2)$ & $31(19.3)$ & 0.06 \\
\hline Central nervous system & 0 & $5(3.1)$ & $<0.01$ \\
\hline Abdominal & 0 & $4(2.5)$ & 0.01 \\
\hline Genitourinary & $94(26.9)$ & $22(13.7)$ & $<0.01$ \\
\hline Soft tissue after trauma & $8(2.3)$ & $5(3.1)$ & 0.56 \\
\hline Epistaxis & $63(18.1)$ & $16(9.9)$ & 0.01 \\
\hline Hemoptysis & $5(1.4)$ & $2(1.2)$ & 1.00 \\
\hline Oral cavity & $60(17.2)$ & $10(6.2)$ & $<0.01$ \\
\hline Hemarthrosis & 0 & $2(1.2)$ & 0.09 \\
\hline Conjunctival & $24(6.9)$ & $1(0.6)$ & $<0.01$ \\
\hline Ear & $6(1.7)$ & 0 & 0.18 \\
\hline Operative wound & $2(0.6)$ & $3(1.9)$ & 0.18 \\
\hline
\end{tabular}

vitamin $\mathrm{K}$ in cases of bleeding during the use of VKA ranges from $19 \%$ to $27 \% .^{12,19}$ In our institution, it was used in $50 \%$ of cases.

The independent variables with stronger association with hospitalization were drop in hemoglobin and need for blood transfusion. This is probably explained by the fact that more severe bleeding requires more medical care and an increased observation period.

Our study is subject to some limitations. The fact that this was a single-center, cross-sectional study, including a convenience sample by the review of electronic medical records, may be associated with registration bias. In addition, bleeding complications among VKA users may be been underestimated, since the study was conducted in a cardiology hospital, and many patients may have sought general hospitals for these events.

\section{Conclusion}

Drop in hemoglobin, heart failure, supra-therapeutic INR, gastrointestinal bleeding, and need for blood transfusion were associated with the need for hospitalization by VKA users who seek emergency care due to bleeding. Identification of these factors in the initial evaluation would help to define which patients will demand more intensive care.

\section{Author contributions}

Analysis and interpretation of the data: Chiaparini AF, Rabaioli PSB, Slaviero JV, Tem-Pass CS, Fontana Filho HA. Statistical analysis: Chiaparini AF, Almeida ED, Leiria TLL. Writing of the manuscript: Chiaparini AF, Leiria TLL, Castro I. Critical revision of the manuscript for intellectual content: Chiaparini AF, Leiria TLL, Castro I. Acquisition of data: Slaviero J. Analysis and interpretation of the data: Slaviero J.

\section{Potential Conflict of Interest}

No potential conflict of interest relevant to this article was reported.

\section{Sources of Funding}

This study was funded by researchers' own resources.

\section{Study Association}

This article is part of the thesis of master submitted by Alan Chiaparini, from Fundação Universitária de Cardiologia. 
Table 4 - Bleeding characteristics of patients who were hospitalized or not after emergency care $(\mathrm{n}=510)$

\begin{tabular}{|c|c|c|c|}
\hline & $\begin{array}{l}\text { Discharged from the emergency department } \\
\qquad(\mathrm{n}=349)\end{array}$ & $\begin{array}{l}\text { Hospital Admission } \\
\qquad(\mathrm{n}=161)\end{array}$ & p \\
\hline Therapeutic range of INR, n (\%) & & & $<0.01$ \\
\hline Subtherapeutic & $27(7.7)$ & $8(5.0)$ & \\
\hline Therapeutic & $76(21.8)$ & $7(4.3)$ & \\
\hline Supratherapeutic & $246(70.5)$ & $146(90.7)$ & \\
\hline Drop in hemoblogin, n (\%) & $27(7.7)$ & $107(66.5)$ & $<0.01$ \\
\hline Use of vitamin K, n (\%) & $136(39)$ & $121(75.2)$ & $<0.01$ \\
\hline Blood transfusion, $\mathrm{n}(\%)$ & $6(1.7)$ & $77(47.8)$ & $<0.01$ \\
\hline Plasma, n (\%) & $1(0.3)$ & $38(23.6)$ & $<0.01$ \\
\hline BARC & & & $<0.01$ \\
\hline I & $171(49)$ & $3(1.9)$ & \\
\hline II & $170(48.7)$ & $69(42.9)$ & \\
\hline IIIa & $7(2)$ & $47(29.3)$ & \\
\hline $\mathrm{IIIb}$ & $1(0.3)$ & $30(18.6)$ & \\
\hline IIIc & 0 & $6(3.7)$ & \\
\hline IV & 0 & 0 & \\
\hline Va & 0 & $5(3.1)$ & \\
\hline $\mathrm{Vb}$ & 0 & $1(0.6)$ & \\
\hline GUSTO & & & $<0.01$ \\
\hline Mild & $343(98.3)$ & $73(45.3)$ & \\
\hline Moderate & $6(1.7)$ & 55 (34.2) & \\
\hline Severe & $0(0.9)$ & $33(19)$ & \\
\hline
\end{tabular}

INR supraterapêutico

Supratherapeutic INR

Gastrointestinal Bleeding

Drop in Hemoglobin

Heart Failure

Blood Transfusion

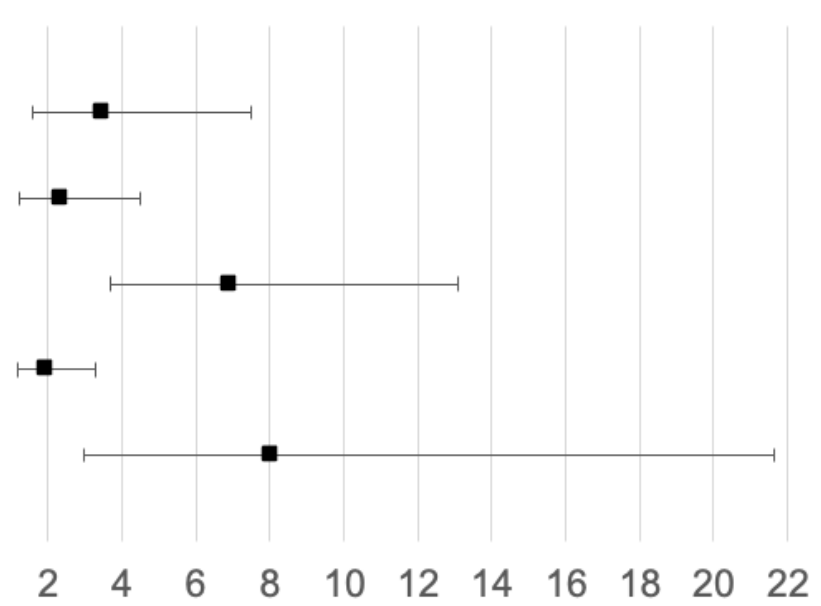

Figure 1 - Forest Plot representing the Odds Ratio and confidence interval (95\%) of the predictive factors for hospitalization of vitamin $\mathrm{K}$ users who sought emergency care for bleeding 


\section{Ethics approval and consent to participate}

This study was approved by the Ethics Committee of the IC/FUC under the protocol number 4.225.884. All the procedures in this study were in accordance with the 1975 Helsinki Declaration, updated in 2013. Informed consent was obtained from all participants included in the study.

\section{References}

1. January CT, Wann LS, Calkins H, Chen LY, Cigarroa JE, Cleveland JC Jr, et al. 2019 AHA/ACC/HRS Focused Update of the 2014 AHA/ACC/ HRS Guideline for the Management of Patients With Atrial Fibrillation A Report of the American College of Cardiology/American Heart Association Task Force on Clinical Practice Guidelines and the Heart Rhythm Society in Collaboration With the Society of Thoracic Surgeons. Circulation. 2019;140(2):125-51. doi: 10.1161/CIR.0000000000000665.

2. Hart RG, Pearce LA, Aguilar MI. Meta-Analysis: Antithrombotic Therapy to Prevent Stroke in Patients Who have Nonvalvular Atrial Fibrillation. Ann Intern Med. 2007;146(12):857-67. doi: 10.7326/0003-4819-146-12 200706190-00007.

3. Hindricks G, Potpara T, Dagres N, Arbelo E, Bax JJ, Blomström-Lundqvist C, et al. 2020 ESC Guidelines for the Diagnosis and Management of Atrial Fibrillation Developed in Collaboration with the European Association for Cardio-Thoracic Surgery (EACTS): The Task Force for the Diagnosis and Management of Atrial Fibrillation of the European Society of Cardiology (ESC) Developed with the Special Contribution of the European Heart Rhythm Association (EHRA) of the ESC. Eur Hear J. 2021;42(5):373-498. doi: 10.1093/eurheartj/ehaa612.

4. Otto CM, Nishimura RA, Bonow RO, Carabello BA, Erwin JP 3rd, Gentile F, et al. 2020 ACC/AHA Guideline for the Management of Patients With Valvular Heart Disease: Executive Summary: A Report of the American College of Cardiology/American Heart Association Joint Committee on Clinical Practice Guidelines. Circulation. 2021;143(5):35-71. doi: 10.1161/ CIR.0000000000000932.

5. Ageno W, Gallus AS, Wittkowsky A, Crowther M, Hylek EM, Palareti G. Oral Anticoagulant Therapy: Antithrombotic Therapy and Prevention of Thrombosis, 9th ed: American College of Chest Physicians EvidenceBased Clinical Practice Guidelines. Chest. 2012;141(2 Suppl):44-88. doi 10.1378/chest.11-2292.

6. Eikelboom JW, Connolly SJ, Brueckmann M, Granger CB, Kappetein AP, Mack MJ, et al. Dabigatran Versus Warfarin in Patients with Mechanical Heart Valves. N Engl J Med. 2013;369(13):1206-14. doi: 10.1056/NEJMoa1300615.

7. Baumgartner H, Falk V, Bax JJ, Bonis M, Hamm C, Holm PJ, et al. 2017 ESC/EACTS Guidelines for the Management of Valvular Heart Disease. Eur Heart J. 2017;38(36):2739-91. doi: 10.1093/eurheartj/ehx391.

8. Shehab N, Lovegrove MC, Geller AI, Rose KO, Weidle NJ, Budnitz DS, US Emergency Department Visits for Outpatient Adverse Drug Events, 2013-2014. JAMA. 2016;316(20):2115-25. doi: 10.1001/jama.2016.16201.

9. Jakobsen M, Kolodziejczyk C, Fredslund EK, Poulsen PB, Dybro L, Johnsen SP. Costs of Major Intracranial, Gastrointestinal and Other

Bleeding Events in Patients with Atrial Fibrillation - A Nationwide Cohort Study. BMC Health Serv Res. 2017;17(398):1-11. doi: 10.1186/ s12913-017-2331-z.

10. Sayhan MB, Oğuz S, Yüksel V, Hüseyin S, Sayhan ES, Yağcl G. The Analysis of Patients Admitted to the Emergency Department Due to Complications Related to Warfarin Treatment. J Acad Emerg Med. 2014;13(4):194-8. doi:10.5152/jaem.2014.075.

11. Shehab N, Sperling LS, Kegler SR, Budnitz DS. National Estimates of Emergency Department Visits for Hemorrhage-Related Adverse Events from Clopidogrel Plus Aspirin and from Warfarin. Arch Intern Med. 2010;170(21):1926-33. doi: 10.1001/archinternmed.2010.407.

12. Singer AJ, Quinn A, Dasgupta N, Thode HC Jr. Management and Outcomes of Bleeding Events in Patients in the Emergency Department Taking Warfarin or a Non-Vitamin K Antagonist Oral Anticoagulant. J Emerg Med. 2017;52(1):1-7. doi: 10.1016/j.jemermed.2016.09.028.

13. Meeker E, Dennehy CE, Weber EJ, Kayser SR. Emergency Department Management of Patients on Warfarin Therapy. Ann Emerg Med. 2011;58(2):192-9. doi: 10.1016/j.annemergmed.2011.01.018.

14. Becattini C, Franco L, Masotti L, Nitti C, Cattinelli S, Cappelli R, et al. Clinical Management and Outcome of Major Bleeding in Patients on Treatment with Vitamin K Antagonists. Eur J Intern Med. 2016;33:47-54. doi: 10.1016/j.ejim.2016.05.019.

15. Conti A, Renzi N, Catarzi S, Mazzucchelli M, Covelli A, Pampana A, et al. Bleeding Events in Patients 75 Years of Age and Older Under LongTerm Anticoagulant Therapy: A Real-life Study. Crit Pathw Cardiol. 2020;19(3):131-8. doi: 10.1097/HPC.0000000000000205.

16. Budnitz DS, Lovegrove MC, Shehab N, Richards CL. Emergency Hospitalizations for Adverse Drug Events in Older Americans. N Engl J Med. 2011;365(21):2002-12. doi: 10.1056/NEJMsa1103053.

17. Kauppila M, Backman JT, Niemi M, Lapatto-Reiniluoto O. Incidence, Preventability, and Causality of Adverse Drug Reactions at a University Hospital Emergency Department. Eur J Clin Pharmacol. 2021;77(4):64350. doi: 10.1007/s00228-020-03043-3.

18. Anthony CJ, Karim S, Ackroyd-Stolarz S, Fry A, Murphy NG, Christie $R$, et al. Intensity of Anticoagulation with Warfarin and Risk of Adverse Events in Patients Presenting to the Emergency Department. Ann Pharmacother. 2011;45(7-8):881-7. doi: 10.1345/aph.1P670.

19. Bouget J, Oger E, Nicolas N. Emergency Admissions for Major Haemorrhage Associated with Antithrombotics: A CohortStudy. Thromb Res. 2015;135(1):84-9. doi: 10.1016/j.thromres.2014.10.029. 